\title{
The Orientation of Certain Root-nodule Bacteria at Interfaces, Including Legume Root-hair Surfaces
}

\author{
By K. C. MARSHALL, ${ }^{*}$ R. H. CRUICKSHANK AND H. V. A. BUSHBY† \\ Department of Agricultural Science, University of Tasmania, \\ Hobart, Tasmania 700I, Australia
}

(Received I4 April 1975; revised 20 June 1975)

The observation by one of us (H.V.A.B.) that some isolates of root-nodule bacteria formed rosettes in culture (Fig. I $a$ ) prompted an investigation of the orientation of bacteria at interfaces. By analogy with other rosette-forming bacteria (Marshall \& Cruickshank, 1973), it was expected that these bacteria would orient themselves approximately at right angles to interfaces. The behaviour of a number of species of Rhizobium at oil-water interfaces was examined by the technique described by Marshall \& Cruickshank (I973) and, as shown in Fig. I (b), cells of Rhizobium lupini UTI 2 do orient themselves approximately at right angles to an oil-water interface. Similar behaviour at oil-water interfaces was found with a range of different species of root-nodule bacteria. Some, but not all, of these formed rosettes. The exact orientation of very short rods at oil-water interfaces was difficult to ascertain because of the glare at the interface when using phase-contrast microscopy.

Adhesion of rhizobia to legume root hairs was examined, using sterile subterranean clover (Trifolium subterraneum L.), pea (Pisum sativum L.) and soybean (Glycine max Merrill). Surface-sterilized seeds were allowed to germinate and form root hairs on a solid-agar surface before transfer to tubes containing sterile nitrogen-free liquid (Fåhraeus, 1957). The seedlings were supported on stainless steel grids with the roots immersed in the liquid. Following inoculation with an appropriate strain of Rhizobium, the plants were incubated for I to 3 days, under illumination, before harvesting. The roots were thoroughly rinsed to remove all but the firmly adhering bacteria. Portions of the roots, with root hairs attached, were fixed in $5 \%$ glutaraldehyde followed by $\mathrm{I} .0 \% \mathrm{OsO}_{4}$, both contained in collidine buffer $(0 \cdot \mathrm{I} \mathrm{M}, \mathrm{pH} 7 \cdot 2)$. They were dehydrated either through an alcohol series followed by embedding in Spurr's medium, or through propylene oxide followed by embedding in Araldite. Thin sections were stained with uranyl acetate and lead citrate when embedded in Spurr's medium, or with permanganate and lead citrate when embedded in Araldite. Sections of the root hairs were examined in an AEI EM6 electron microscope at an accelerating voltage of $60 \mathrm{kV}$. The non-specific attachment of rhizobia to solid surfaces was examined by the method of Marshall \& Cruickshank (1973), except that blocks of Spurr's medium were used instead of Araldite.

A perpendicular orientation of the bacteria at a root hair surface is shown for $R$. trifolii SU297A on subterranean clover (Fig. I $c$ ) and has been observed with other species of fastand slow-growing rhizobia. As noted by Marshall \& Cruickshank (1973), the pole of each bacterium was attached to the surface by some form of bridging polymer. The electron micrographs were deliberately over-exposed to emphasize this polymer. Unlike the Flexi-

* Present address: School of Microbiology, University of New South Wales, Kensington, New South Wales 2033, Australia.

$\dagger$ Present address: Division of Tropical Agronomy, C.S.I.R.O., St. Lucia, Queensland 4067, Australia. 

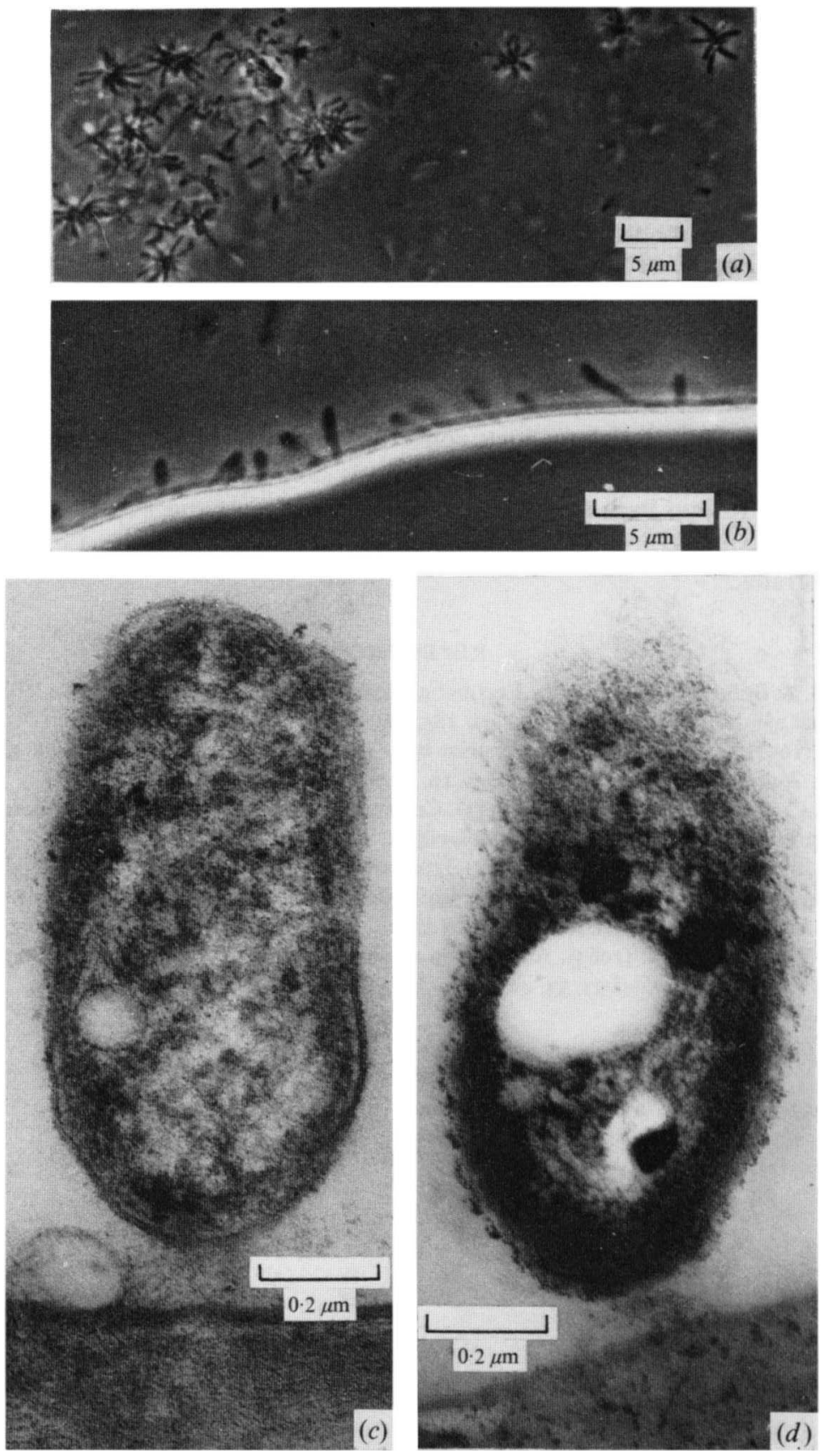

Fig. I. (a), (b) Phase-contrast micrographs of (a) rosettes formed by Rhizobium japonicum QA372, and (b) the orientation of $R$. lupini UTI 2 at an oil-water interface. $(c),(d)$ Electron micrographs showing adhesion of $(c) R$. trifolii SU297A to a subterranean clover root hair, and $(d) R$. leguminosarum TAIO2 to a Spurr's medium surface. 
bacter and Hyphomicrobium cultures described by Marshall \& Cruickshank (1973), it is not certain whether one or both poles of these strains of Rhizobium are attracted to the interface. A perpendicular orientation of rhizobia at root or root hair surfaces has been noted by Sahlman \& Fåhraeus (1963), Menzel, Uhlig \& Weichsel (1972), and B. B. Bohlool and D. Hubbell (personal communications).

Bohool \& Schmidt (1974) suggested that specific interactions between root-nodule bacteria and the root hairs of the host legume may involve binding between legume lectins and the bacteria. That the mode of attachment of the rhizobia reported here is a non-specific phenomenon is illustrated by an identical mode of attachment to the surface of Spurr's medium (Fig. I $d$ ). We have no evidence to suggest that the perpendicular orientation of these bacteria at root hair surfaces is of any significance in the process of root hair infection. If, however, the presence of the bridging polymer at one pole of the bacterium indicates a more 'leaky' condition at the pole, then this mode of attachment could provide a means for the localization of bacterial products concerned with some phase of the infection process.

We thank Mrs Robyn Page for technical assistance. This project was supported by grants from the Australian Research Grant Committee and the Rural Credits Fund of the Reserve Bank of Australia.

\section{REFERENCES}

Bohlool, B. B. \& SCHMIDT, E. L. (1974). Lectins: a possible basis for specificity in the Rhizobium-legume root nodule symbiosis. Science, New York 185, 269-271.

FÅHraEUS, G. (1957). The infection of clover root hairs by nodule bacteria, studied by a simple glass slide technique. Journal of General Microbiology 16, 374-381.

Marshall, K. C. \& CruickshanK, R. H. (1973). Cell surface hydrophobicity and the orientation of certain bacteria at interfaces. Archiv für Mikrobiologie 9r, 29-40.

Menzel, G., Uhlig, H. \& Weichsel, G. (1972). Úber die Besiedlung der Wurzeln einiger Leguminosen und Nichtleguminosen mit Rhizobien und anderen Bodenbakterien. Zentralblatt für Bakteriologie, Parasitenkunde, Infektionskrankheiten und Hygiene (Abteilung II) 127, 348-358.

Sahlman, K. \& Fåhraeus, G. (1963). An electron microscope study of root-hair infection by Rhizobium. Journal of General Microbiology 33, 425-427. 